\title{
Extracranial and Intracranial Occlusive Lesion in Acute Ischemic Stroke is Still a Therapeutic Challenge: A Case Report
}

\author{
Sirajee Shafiqul Islam¹, Kazi Mohibur Rahman², Sharif Uddin Khan ${ }^{3}$, Dewan Md. Elyas,,
} Khairul Kabir Patwary ${ }^{5}$, Muhammad Abdul Momen Khan ${ }^{6}$, Md. Amir Hossain ${ }^{7}$, ATM Hasibul Hasan ${ }^{8}$

\footnotetext{
${ }^{1}$ Associate Professor, Department of Interventional Neurology, National Institute of Neurosciences \& Hospital, Dhaka, Bangladesh; ${ }^{2}$ Associate Professor, Department of Interventional Neurology, National Institute of Neurosciences \& Hospital, Dhaka, Bangladesh; ${ }^{3}$ Associate Professor, Department of Interventional Neurology, National Institute of Neurosciences \& Hospital, Dhaka, Bangladesh; ${ }^{4}$ Assistant Professor, Department of Interventional Neurology, National Institute of Neurosciences \& Hospital, Dhaka, Bangladesh; ${ }^{5}$ Associate Professor, Department of Interventional Neurology, National Institute of Neurosciences \& Hospital, Dhaka, Bangladesh; ${ }^{6}$ Assistant Professor, Department of Interventional Neurology, National Institute of Neurosciences \& Hospital, Dhaka, Bangladesh; ${ }^{7}$ Assistant Professor, Department of Interventional Neurology, National Institute of Neurosciences \& Hospital, Dhaka, Bangladesh; ${ }^{8}$ Registrar, Department of Interventional Neurology, National Institute of Neurosciences \& Hospital, Dhaka, Bangladesh
}

[Received: 12 August 2019; Accepted: 20 October 2019; Published: 1 January 2019]

\begin{abstract}
A 55-year-old male presented with complete left-sided weakness of the body with a National Institutes of Health Stroke Scale (NIHSS) 15 and Alberta Stroke Program Early Computed Tomography (ASPECT) score 8 and occlusion of the right middle cerebral artery (MCA) in the M1 segment on Computed Tomography Angiography (CTA). Intravenous thrombolysis (IVT) was not performed as symptoms developed at sleep. Mechanical Thrombectomy was performed after 4.5 hours of the symptom onset with recanalization of Thrombolysis in Cerebral Infarction (TICI classification 2b). [Journal of National Institute of Neurosciences Bangladesh, 2019;5(2): 90-94]
\end{abstract}

Keywords: Acute Ischemic stroke, mechanical thrombectomy, tandem lesion, stent retriever

Correspondence: Dr.Sirajee Shafiqul Islam,Associate Professor, Department of Interventional Neurology, National Institute of Neurosciences \& Hospital, Dhaka, Bangladesh; Email: sirajee.neuro@gmail.com; Cell no.: +880171166684

Conflict of interest: There is no conflict of interest relevant to this paper to disclose.

Contribution to authors: All authors have contributed from the diagnosis, management and monitoring of the patient. Manuscript writing was performed bySirajee SI.

How to cite this article: Islam SS, Rahman KM, Khan SU, Elyas DM, Patwary KK, Khan MAM, Hossain MA, Hasan ATMH Endovascular Recanalization by Mechanical Thrombectomy in Tandem Extracranial and Intracranial Occlusive Lesion in Acute Ischemic Stroke is Still a Therapeutic Challenge:A Case Report. J NatlInstNeurosci Bangladesh, 2019;5(1): 90-94

Copyright: (C2019. Islam et al. Published by Journal of National Institute of Neurosciences Bangladesh. This article is published under the Creative Commons CC BY-NC License (https://creativecommons.org/licenses/by-nc/4.0/). This license permits use, distribution and reproduction in any medium, provided the original work is properly cited, and is not used for commercial purposes.

\section{Introduction}

In acute ischemic stroke IVT has been the most important therapy since last two decades ${ }^{1}$. The range of efficacy is limited in IVT due to a narrow time window of 4.5 hours after symptom onset and also for contraindications like oral anticoagulation, recent surgery etc. Furthermore, recanalization rates and outcome in patients with large clots and proximal vessel occlusion are poor after IVT $^{2}$.

Currently, a review of published data from several randomized clinical trials demonstrated superiority of endovascular treatment over IVT in patients with acute ischemic stroke caused by a proximal vessel occlusion in the anterior circulation ${ }^{3}$. Selection of patients based on imaging-especially targeting for diffusion/perfusion mismatch and excluding patients with a large infarct core-has been shown to successfully avoid futile interventions in all these trials ${ }^{4}$.

Currently the time window for favorable outcome after endovascular treatment is not well defined. Endovascular treatment with stent retriever thrombectomy is recommended up to 8 hours after symptom onset ${ }^{5}$.

Acute tandem occlusions of the cervical internal carotid artery and an intracranial large vessel present treatment 
challenges. In this case we have shown that distal lesion recanalization first then proximal lesion stent angioplasty also could be an option.

\section{Case Presentation}

A 54-year old, right-handed male admitted in the National Institute of Neurosciences and Hospital with the history of waked from sleep with abnormal sound by mouth, semi-consciousness and complete weakness in the left side of the body. The patient also experienced Ischemic stroke with mild left sided weakness about two months back was noticed by the patient's attendance. On admission his NISSH was 15 . Computed tomography (Figure A) showed Alberta Stroke Program Early Computed Tomography (ASPECT) score 8 and Computed tomography angiography (CTA) showed stenosis $(90 \%)$ at the proximal C1 segment (Figure B) of right Internal carotid artery (ICA) and total occlusion of M1 segment (Figure C) of the right middle cerebral artery (MCA). After taking consent from the family patient was shifted to DSA cathlab. With all aseptic precaution a $6 \mathrm{~F}$ guiding catheter was introduced through right femoral puncture and placed in right CCA. Balloon Angioplasty was done by balloon $(3 \mathrm{~mm} \times 20 \mathrm{~mm})$ at the proximal RICA. Then the guiding was advanced over guiding wire (terumo,'035") up to the petrous segment. M1 segment of right MCA was gently catheterized with a Rebar18 catheter. After removal of the microguidewire, a self-expanding Solitaire stent $(4 \mathrm{~mm}$ diameter, $40 \mathrm{~mm}$ length) was inserted under continuous slow flush with saline solution to the distal end of the microcatheter and was deployed by slowly pulling back the microcatheter. Correct deployment of the Solitaire stent over the whole length of the thrombus was observed under continuous fluoroscopy. Stent was incubated for several minutes for encasement of the clot by stent. Another $6 \mathrm{~F}$ guiding catheter was introduced through left femoral puncture upto the right Common carotid artery through which a balloon $(4 \mathrm{~mm} \times 20 \mathrm{~mm})$ was placed at the $\mathrm{C} 2$ segment. After several minutes of incubation and with the rotating hemostatic valve tightly closed, the balloon was, a $50 \mathrm{ml}$ Luer lock syringe was used for high volume aspiration through the right femoral $6 \mathrm{~F}$ guiding catheter during withdrawal of the open Solitaire stent and the microcatheter into the guide catheter. Thrombus (Figure E) was captured by the Solitaire stent. Angiography after withdrawal of Solitaire showed a complete recanalization (Figure D) of the previously occluded right MCA (TICI classification 2b). Finally a Carotid Stent Protas $(6-8 \mathrm{~mm}$ $\mathrm{x} 40 \mathrm{~mm}$ ) was deployed at $\mathrm{C} 1$ segment and proximal right ICA recanalized (Figure F) done. Patient was shifted to the ICU. Aspirin $300 \mathrm{mg}$ was administered by nasogastric tube, CT scan of head was done after one hour and observed no intra cranial hemorrhage. Patient was given

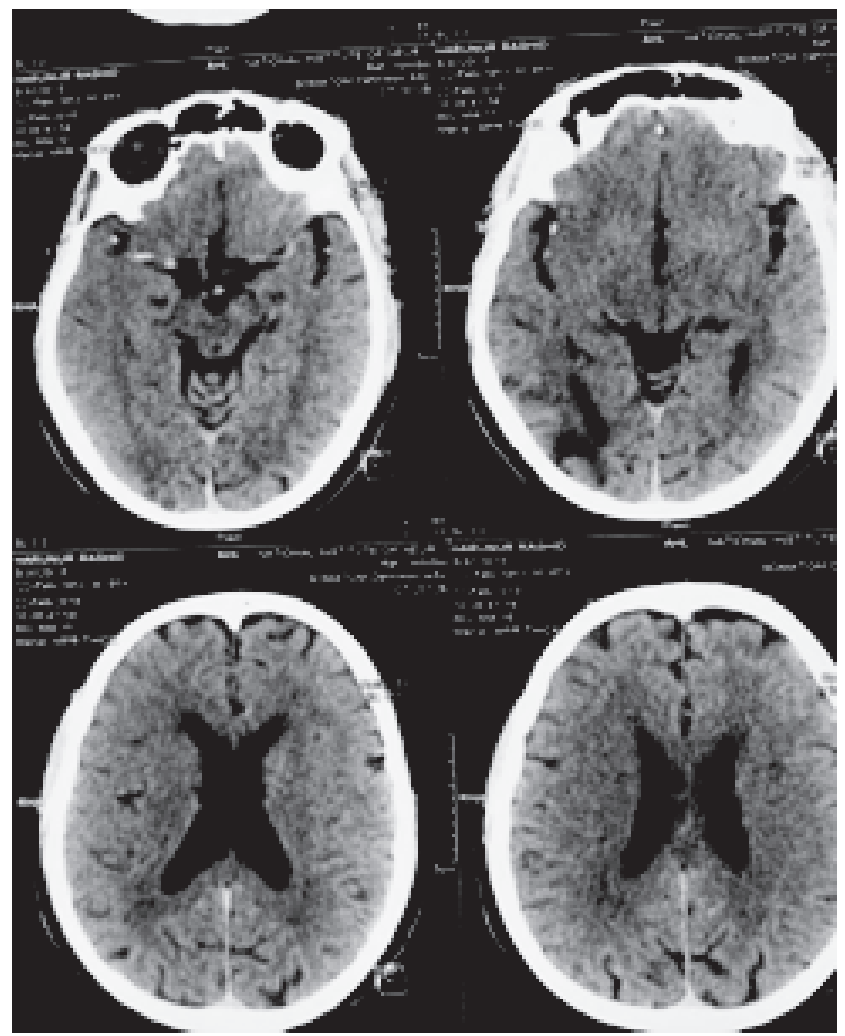

(A) CT scan of head

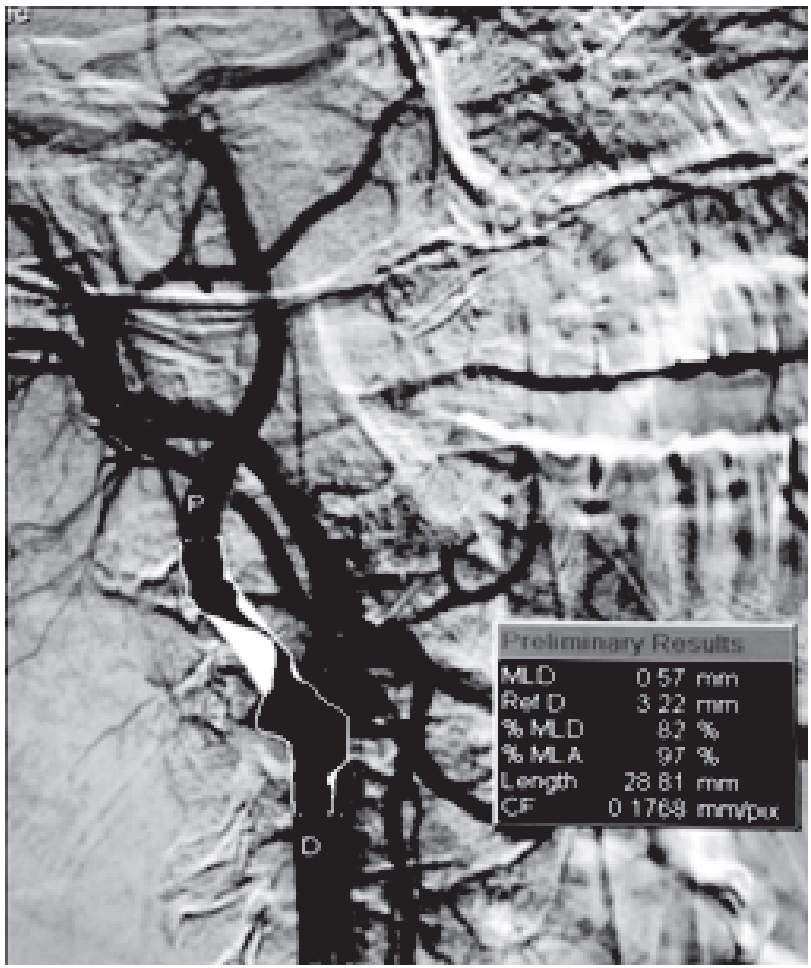

(B) Proximal stenosis 
physiotherapy in recovery ward and was discharged after 30 days with mild weakness (M-4/5) in the left side of the body.
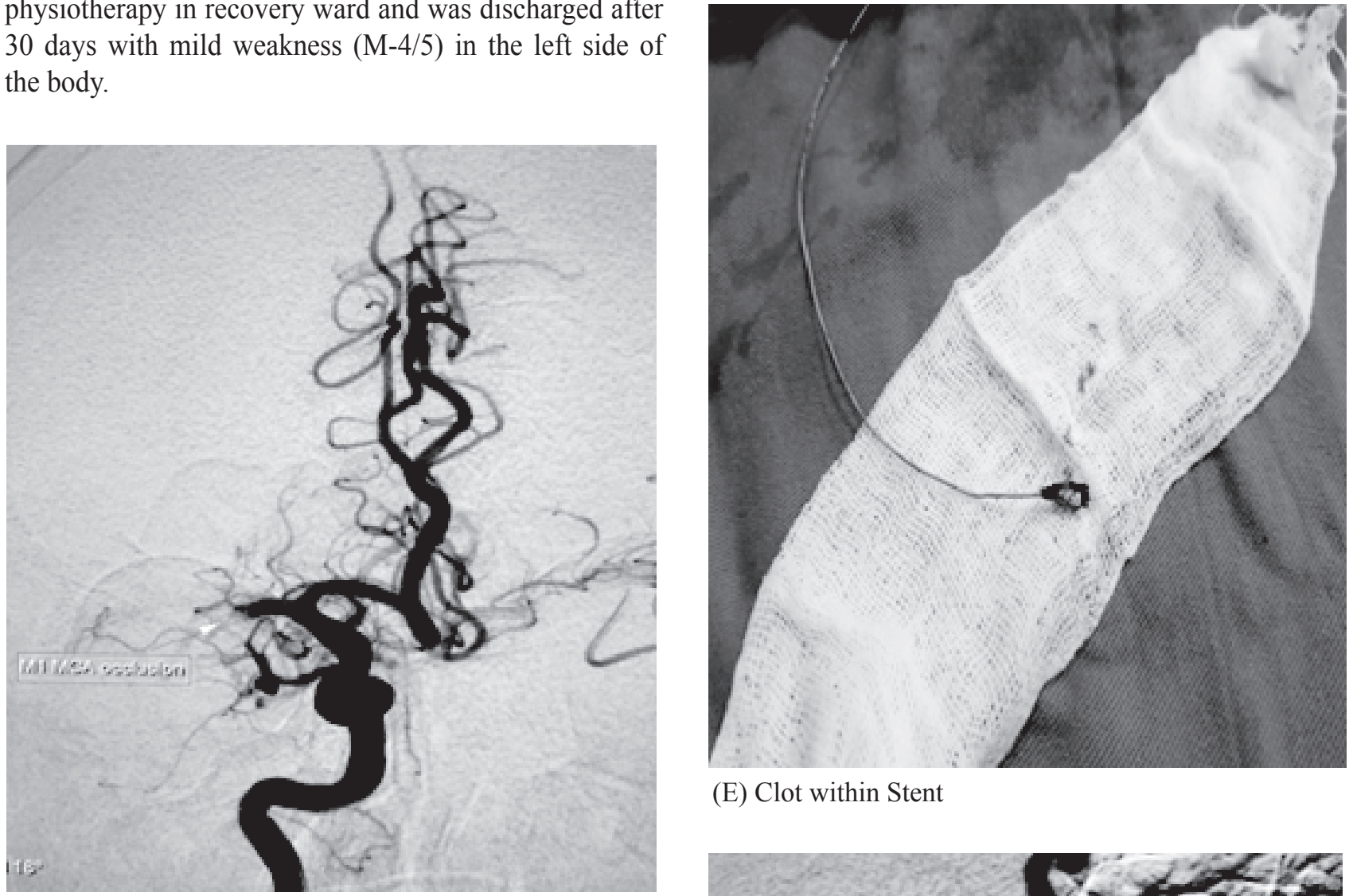

(E) Clot within Stent

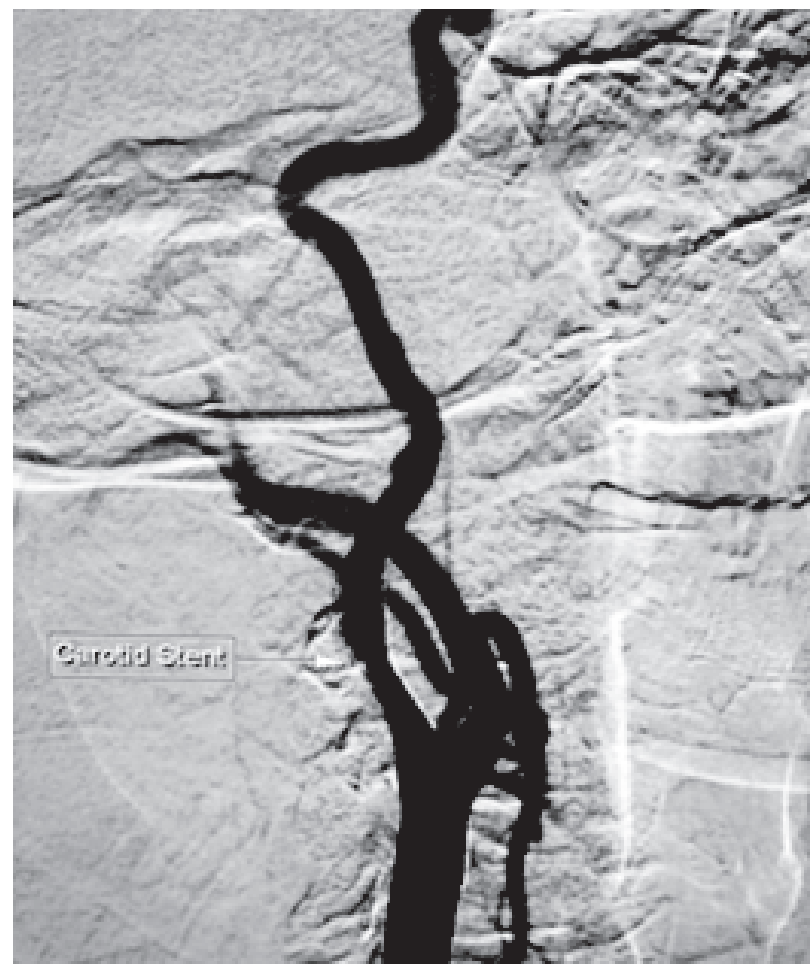

(F) Stenting in Cervical Stenosis

\section{Discussion}

In acute stroke patients with occlusion of large vessels in the anterior circulation, mechanical thrombectomy improves functional outcome ${ }^{6}$. Recanalization is 
associated with better outcome and recanalization rates with mechanical techniques have been shown to be superior to pharmacological treatment only ${ }^{6}$. Patients with mild or rapidly improving symptoms, but proximal vessel occlusions have a poor outcome when left untreated ${ }^{6}$. In an earlier study especially proximal vessel occlusion and NIHSS $\geq 10$ were predictors of poor outcome patients with stroke? ${ }^{7}$. Therefore, rapid identification and treatment of these patients with large vessel occlusion and low NIHSS with decision against treatment in the acute phase, transferal to a stroke center with endovascular treatment facilities for further monitoring is highly recommended.

However, the time window for favorable outcome after endovascular treatment is not well defined. Only very recently first results of the DAWN study-presented on the $3^{\text {rd }}$ European Stroke Organisation Conference in Prague-showed that removal of a clot by endovascular thrombectomy within up to 24 hours after onset of signs and symptoms reduced the disability in selected stroke patients, such as wake-up strokes ${ }^{8}$. As demonstrated by Flint et al. and confirmed by Jovin et al. earlier, endovascular treatment with stent retriever thrombectomy within 8 hours after symptom onset is safe and reduces the severity of poststroke disability ${ }^{5,9}$.

Tandem extra and intracranial lesions of the anterior circulation, i.e., the simultaneous occurrence of an intracranial large vessel occlusion and a high-grade stenosis or occlusion of the ipsilateral proximal internal carotid artery (ICA), account for $10-20 \%$ of large vessel strokes ${ }^{10,11}$. This pathology is particularly challenging as response rates to intravenous thrombolysis are low and the prognosis is often poor $^{10,12}$.

Nonetheless, it has yet to be established how the proximal ICA lesion should be approached during MT. There are several possibilities, i.e., stenting, percutaneous transluminal angioplasty (PTA) alone or no treatment of the lesion; yet, all approaches present advantages and drawbacks. Stenting in the acute phase offers a definitive treatment in one step, but necessitates antiplatelet therapy-often in conjunction with intravenous thrombolysis-putting the patient at potentially elevated risk of intracranial hemorrhage or reperfusion injury ${ }^{13-16}$. While simple PTA of the carotid lesion obviates acute antiplatelet therapy, a risk of reperfusion injury persists and the rate of significant restenosis is high ${ }^{17}$. However, delayed treatment of the lesion by endarterectomy or stenting can be utilized in patients with favorable clinical outcomes, which may also help to reduce the number of unnecessary procedures $^{18}$. Not treating the cervical lesion at all has similar potential advantages and in addition may be faster, while eliminating the risk of reperfusion injury. Nevertheless, this strategy must be balanced against the drawback of a potential risk of recurrent cerebral embolism $^{19}$.

Current meta-analyses did not find significant differences in clinical outcomes between patients treated with stenting and patients treated with PTA alone in the acute phase $\mathrm{e}^{20,21}$. Wilson et $\mathrm{al}^{20}$ concluded that most studies "have entirely or partly treated extracranial occlusion with stenting during initial treatment" and that very few focus on angioplastyonly approaches.

\section{Conclusion}

Tandem occlusion in the setting of acute ischemic stroke remains a therapeutic challenge. However, high recanalization rate is possible using acute intracranial thrombectomy by stent retriever in distal occlusion and carotid artery stenting in proximal stenosis, with acceptable morbidity and mortality rates.

\section{References}

1. Hacke W, Kaste M, Bluhmki E, Brozman M, Dávalos A, Guidetti D, Larrue V, Lees KR, Medeghri Z, Machnig T, Schneider D. Thrombolysis with alteplase 3 to 4.5 hours after acute ischemic stroke. New England journal of medicine. 2008;359(13):1317-29. 2. Riedel CH, Zimmermann P, Jensen-Kondering U, Stingele R, Deuschl G, Jansen O. The importance of size: successful recanalization by intravenous thrombolysis in acute anterior stroke depends on thrombus length. Stroke. 2011;42(6):1775-7.

3. Goyal M, Menon BK, Van Zwam WH, Dippel DW, Mitchell PJ, Demchuk AM, Dávalos A, Majoie CB, Van Der Lugt A, De Miquel MA, Donnan GA. Endovascular thrombectomy after large-vessel ischaemic stroke: a meta-analysis of individual patient data from five randomised trials. The Lancet. 2016;387(10029):1723-31.

4. Lansberg MG, Straka M, Kemp S, Mlynash M, Wechsler LR, Jovin TG, Wilder MJ, Lutsep HL, Czartoski TJ, Bernstein RA, Chang CW. MRI profile and response to endovascular reperfusion after stroke (DEFUSE 2): a prospective cohort study. The Lancet Neurology. 2012;11(10):860-7.

5. Jovin TG, Chamorro A, Cobo E, de Miquel MA, Molina CA, Rovira A, San Román L, Serena J, Abilleira S, Ribó M, Millán M. Thrombectomy within 8 hours after symptom onset in ischemic stroke. New England Journal of Medicine. 2015;372(24): 2296-306.

6. Wahlgren N, Moreira T, Michel P, Steiner T, Jansen O, Cognard C, Mattle HP, van Zwam W, Holmin S, Tatlisumak T, Petersson J. Mechanical thrombectomy in acute ischemic stroke: Consensus statement by ESO-Karolinska Stroke Update 2014/2015, supported by ESO, ESMINT, ESNR and EAN. International Journal of Stroke. 2016;11(1):134-47.

7. Nedeltchev K, Schwegler B, Haefeli T, Brekenfeld C, Gralla J, Fischer U, Arnold M, Remonda L, Schroth G, Mattle HP. Outcome of stroke with mild or rapidly improving symptoms. Stroke. 2007;38(9):2531-5.

8. Jovin TG, Nogueira for the DAWN investigators R. G. Dawn in 
full daylight (DWI or CTP Assessment with clinical mismatch in the triage of wake up and late presenting strokes undergoing neurointervention) 2017

9. Flint AC, Duckwiler GR, Budzik RF, Liebeskind DS, Smith WS. Mechanical thrombectomy of intracranial internal carotid occlusion: pooled results of the MERCI and Multi MERCI Part I trials. Stroke. 2007;38(4):1274-80.

10. Rubiera M, Ribo M, Delgado-Mederos R, Santamarina E, Delgado P, Montaner J, Alvarez-Sabín J, Molina CA. Tandem internal carotid artery/middle cerebral artery occlusion: an independent predictor of poor outcome after systemic thrombolysis. Stroke. 2006;37(9):2301-5.

11. Grau AJ, Weimar C, Buggle F, Heinrich A, Goertler M, Neumaier S, Glahn J, Brandt T, Hacke W, Diener HC. Risk factors, outcome, and treatment in subtypes of ischemic stroke: the German stroke data bank. Stroke. 2001;32(11):2559-66.

12. Kim YS, Garami Z, Mikulik R, Molina CA, Alexandrov AV. Early recanalization rates and clinical outcomes in patients with tandem internal carotid artery/middle cerebral artery occlusion and isolated middle cerebral artery occlusion. Stroke. 2005;36(4):869-71

13. Behme D, Mpotsaris A, Zeyen P, Psychogios MN, Kowoll A, Maurer CJ, Joachimski F, Liman J, Wasser K, Kabbasch C, Berlis A. Emergency stenting of the extracranial internal carotid artery in combination with anterior circulation thrombectomy in acute ischemic stroke: a retrospective multicenter study. American Journal of Neuroradiology. 2015;36(12):2340-5.

14. Zinkstok SM, Roos YB. Early administration of aspirin in patients treated with alteplase for acute ischaemic stroke: a randomised controlled trial. Lancet 2012;380:731-737

15. Mpotsaris A, Kabbasch C, Borggrefe J, Gontu V, Soderman M.
Stenting of the cervical internal carotid artery in acute stroke management: the karolinska experience. Interv.Neuroradiol 2017;23:159-65

16. Mpotsaris A, Bussmeyer M, Buchner H, Weber W. Clinical outcome of neurointerventional emergency treatment of extra- or intracranial tandem occlusions in acute major stroke: antegrade approach with wallstent and solitaire stent retriever. ClinNeuroradiol 2013;23:207-15

17. McCabe DJH, Pereira AC, Clifton A, Bland JM, Brown MM, CAVATAS Investigators. Restenosis after carotid angioplasty, stenting, or endarterectomy in the Carotid and Vertebral Artery Transluminal Angioplasty Study (CAVATAS). Stroke 2005:36:281-6

18. Akpinar CK, Gürkaş E, Aytac E. Carotid angioplasty-assisted mechanical thrombectomy without urgent stenting may be a better option in acute tandem occlusions. Interventional Neuroradiology. 2017;23(4):405-11.

19. Gory B, Sivan-Hoffmann R, Riva R, Labeyrie PE, Huguet N, Nighoghossian N, et al. . Repeated Solitaire mechanical thrombectomy in an acute anterior stroke patient. Rev. Neurol (Paris). 2015;171:682-4

20. Wilson MP, Murad MH, Krings T, Pereira VM, O'Kelly C, Rempel $\mathrm{J}$, et al. . Management of tandem occlusions in acute ischemic stroke - intracranial versus extracranial first and extracranial stenting versus angioplasty alone: a systematic review and meta-analysis. J. NeuroInterventional Surg 2018;10:721-8

21. Coelho A, Lobo M, Gouveia R, Silveira D, Campos J, Augusto R, Coelho N, Canedo A. Overview of evidence on emergency carotid stenting in patients with acute ischemic stroke due to tandem occlusions: a systematic review and meta-analysis. The Journal of cardiovascular surgery. 2018 Jan. 